\title{
Incidence of Mycotoxins in Local and Branded Samples of Chocolates Marketed in Pakistan
}

\author{
Narjis Naz, ${ }^{1}$ Aiza Kashif, ${ }^{1}$ Kinza Kanwal, ${ }^{2}$ and Humayun Ajaz $^{3}$ \\ ${ }^{1}$ Department of Chemistry, Lahore College for Women University, Lahore, Pakistan \\ ${ }^{2}$ Department of Pharmacology and Toxicology, University of Veterinary and Animal Sciences, Lahore, Pakistan \\ ${ }^{3}$ Department of Chemistry, University of Engineering and Technology, Lahore, Pakistan \\ Correspondence should be addressed to Narjis Naz; narjis107@gmail.com
}

Received 9 January 2017; Revised 7 March 2017; Accepted 28 March 2017; Published 21 May 2017

Academic Editor: Vicente M. Gómez-López

Copyright (c) 2017 Narjis Naz et al. This is an open access article distributed under the Creative Commons Attribution License, which permits unrestricted use, distribution, and reproduction in any medium, provided the original work is properly cited.

\begin{abstract}
The present overview was intended to evaluate the degree of total aflatoxins and ochratoxin A contamination in different samples of bitter, dark, milk, and white chocolates marketed in Pakistan. For that exploration, two hundred $(n=200)$ samples of chocolates, 100 branded and 100 local, were analyzed for mycotoxins profile by HPLC-FLD. The outcomes firmly sustained that the majority of the samples were contaminated with aflatoxins and ochratoxin A. The incidence of total aflatoxins and ochratoxin A in branded samples was $83 \%$ and $90 \%$, whereas the local samples showed $91 \%$ and $97 \%$ contamination, respectively. The highest amount of total aflatoxins was found in branded dark chocolates, that is, $2.27 \mu \mathrm{g} / \mathrm{kg}$, and maximum ochratoxin A level was detected white chocolates $(2.06 \mu \mathrm{g} / \mathrm{kg})$. On average, the local white chocolates and dark chocolates faced the highest level of total aflatoxins $(3.35 \mu \mathrm{g} / \mathrm{kg})$ and ochratoxin A $(3.48 \mu \mathrm{g} / \mathrm{kg})$, respectively. The local samples of chocolates were more contaminated with mycotoxins as compared to branded ones accredited to the lack of quality control and quality assurance during the manufacturing as well as packing processes. In recent years, consumption of chocolate is rapidly increasing especially by young generation, so monitoring of mycotoxin occurrence in them is a matter of great concern and more studies are required to comprehend the production of mycotoxins in these products.
\end{abstract}

\section{Introduction}

Chocolates have become an indispensable part of most people's daily routine, eaten anywhere and anytime, whatever the occasion is, as a delicious dessert for over thousands of years worldwide especially among young generation $[1,2]$.

The high intake of chocolates with high cocoa content has been accelerated as it offers important beneficial health effects but, on the other hand, these products tend to have the highest amount of aflatoxins and ochratoxin A $[3,4]$. The atmosphere and storage conditions have been enrolled to have an impact on the development of the expected mycotoxins in food commodities [5].

Mycotoxins, a diverse and pervasive group of compounds produced by certain species of fungus $[6,7]$, are of various types, out of which aflatoxins (AFs) and ochratoxin A (OTA) are of great concern due to their adverse effects on human health $[4,8,9]$. AFs are secondary metabolites that are produced mainly by Aspergillus parasiticus and Aspergillus flavus. They are highly toxic, mutagenic, and carcinogenic compounds [10]. The reason which makes aflatoxin one of the most challenging mycotoxins is the fact that it can be produced by the responsible fungi not only at a preharvest time but also at postharvest stages including process storage and transportation [11, 12]. Aflatoxins, like most of the mycotoxins, are stable compounds. These are not completely destroyed during most food processing operations and lead to the contamination of finished chocolates [13-16]. Ochratoxin A (OTA) is a mycotoxin produced by secondary metabolism of many filamentous species belonging to the genera Aspergillus and Penicillium. Biosynthetically, it is a pentaketide derivative of the dihydrocoumarins family coupled to $\beta$-phenylalanine [17]. It has nephrotoxic, teratogenic, neurotoxic, and hepatotoxic effect and immunosuppressive properties [18]. 
In spite of various research studies on mycotoxins in chocolate and related products from many countries, no information is accessible on mycotoxin contamination in chocolates marketed in Pakistan. Owing to the considerable health hazards linked with them and to ensure a healthy food supply $[19,20]$, the objective of this research work was to estimate the occurrence of mycotoxins, that is, aflatoxin and ochratoxin A, by HPLC in the local and branded samples of chocolate. A number of toxins already have natural fluorescence (e.g., AFs, OTA) and can be detected directly by HPLC-FD.

The outcomes will give some important references to highlight the danger appraisal and scrutinize the quality of chocolates with respect to mycotoxin contamination with the intention of preventing their accumulation in these products.

\section{Materials and Methods}

2.1. Samples and Sampling. Two hundred samples $(n=200)$ of chocolates including 100 local and 100 branded were randomly collected from different markets of Pakistan. All the samples were of different categories, including milk, white, bitter, and dark chocolate bars with high cocoa solid. The samples collected for analysis were destined for human consumption. They were ground and kept at $-20^{\circ} \mathrm{C}$ until analysis. The samples were extracted and scrutinized in triplicate.

2.2. Chemicals and Reagents. HPLC grade acetonitrile, methanol, toluene, phosphate buffered saline (PBS), and glacial acetic acid were purchased from Merck (Germany). Double distilled water was used for the preparation of solutions. Analytical standards of aflatoxin $\mathrm{G}_{1}\left(\mathrm{AFG}_{1}\right)$, aflatoxin $\mathrm{G}_{2}\left(\mathrm{AFG}_{2}\right)$, aflatoxin $\mathrm{B}_{1}\left(\mathrm{AFB}_{1}\right)$, aflatoxin $\mathrm{B}_{2}\left(\mathrm{AFB}_{2}\right)$, and ochratoxin $A$ were purchased from Sigma-Aldrich. The laboratory glass wares used were kept at $10 \%(\mathrm{v} / \mathrm{v})$ nitric acid (Merck, Germany) overnight and rinsed several times with ultrapure water before use.

2.3. Method Validation. The method for the analysis of mycotoxins was reported in literature $[3,19,21]$ and used with little modification. Method validation was conducted based on IUPAC guidelines [22] with the following criteria: limit of detection (LOD), limit of quantification (LOQ), precision, specificity, and linearity. Aflatoxins and ochratoxin A were extracted and detected using immunoaffinity column for cleanup and HPLC-FLD for estimation. The limit of detection was obtained by artificially contaminating the chocolate samples with aflatoxin and ochratoxin $\mathrm{A}$ and the standard deviation was calculated. LOD for $\mathrm{AFB}_{1}$ was $0.10 \mu \mathrm{g} / \mathrm{kg}$, $\mathrm{AFB}_{2}, 0.20 \mu \mathrm{g} / \mathrm{kg}, \mathrm{AFG}_{1}, 0.20 \mu \mathrm{g} / \mathrm{kg}, \mathrm{AFG}_{2} 0.20 \mu \mathrm{g} / \mathrm{kg}$, and OTA, $0.2 \mu \mathrm{g} / \mathrm{kg}$ and the limit of quantification was determined by multiplying standard deviation by 10 . Selectivity or specificity was assessed by comparing the retention times of the spiked chocolate samples with the retention times of the reference standard solutions. Linearity curves were made by plotting concentration against peak area and were defined using a correlation coefficient $\left(R^{2}\right)$. The following calibration solutions were prepared: $\mathrm{AFB}_{1}$ and $\mathrm{AFG}_{1}(0.2-35 \mathrm{ppb}), \mathrm{AFB}_{2}$ and $\mathrm{AFG}_{2}(0.2-8 \mathrm{ppb})$, and OTA $(0.2-30 \mathrm{ppb})$. The precision was evaluated based on RSD. The recovery studies were performed by spiking uncontaminated chocolate samples with 2,4 , and $6 \mu \mathrm{g} / \mathrm{kg}$ of each mycotoxin's (aflatoxins and ochratoxin A) standards. The spiked samples provide high level of recoveries for all mycotoxins.

2.4. Analysis of Aflatoxins $G_{1}, G_{2}, B_{1}$, and $B_{2}$ in Chocolates. 25 grams of the homogenized chocolate sample and $1 \mathrm{~g}$ of $\mathrm{NaCl}$ were extracted in $100 \mathrm{~mL}$ of methanol : water solution $(80: 20$, $\mathrm{v} / \mathrm{v})$. The mixture was shaken for $30 \mathrm{~min}$ by using UltraTurrax Homogenizer (Polytron, Switzerland). Homogenized solutions were filtered through Whatman Number 1 filter paper. $9 \mathrm{~mL}$ of the filtrate was added in phosphate buffered saline $(24 \mathrm{~mL})$ and applied to an Aflatest WB immunoaffinity column (Vicam, USA) at a flow rate of $1 \mathrm{~mL} / \mathrm{min}$. The column was washed with distilled water $(30 \mathrm{~mL})$. Aflatoxins were eluted with methanol $(2 \mathrm{~mL})$ into the amber vials and evaporated to dryness at $40^{\circ} \mathrm{C}$ under a stream of $\mathrm{N}_{2}$. The dry residue was redissolved in methanol: water $(2: 3, \mathrm{v} / \mathrm{v} ; 1 \mathrm{~mL})$ and filtered with the help of Millex PTFE $0.45 \mathrm{~mm}$ (Millipore, USA) for aflatoxin analysis.

HPLC Parameter. An Agilent 1100 series HPLC system (Agilent Technologies, USA) was used with a fluorescence detection set at $362 \mathrm{~nm}$ excitation and $455 \mathrm{~nm}$ emission for aflatoxins $\mathrm{G}_{1}$ and $\mathrm{G}_{2}$. Aflatoxins $\mathrm{B}_{1}$ and $\mathrm{B}_{2}$ were detected at $425 \mathrm{~nm}$ emission. A reverse phase Agilent Technologies C18 (4.6 $\times 250 \mathrm{~mm}, 5.0 \mu \mathrm{m})$ column was used for chromatographic separation. The mobile phase used for aflatoxin analysis was water: methanol:acetonitrile $(300 \mathrm{~mL}: 100 \mathrm{~mL}: 100 \mathrm{~mL}$ $\mathrm{v} / \mathrm{v} / \mathrm{v}$ ) containing $\mathrm{KBr}$ with the concentration of $119 \mathrm{mg} / \mathrm{L}$ and nitric acid. The flow rate was $1 \mathrm{~mL} / \mathrm{min}$ and column temperature was $40^{\circ} \mathrm{C}$. A mixture of aflatoxin standards was used for construction of a five-point calibration curve of peak areas versus concentration $(\mu \mathrm{g} / \mathrm{L})$. The injection volume was $20 \mu \mathrm{L}$ for both standard solution and sample extracts.

\subsection{Analysis of Ochratoxin A in Chocolates}

Sample Cleanup Applied for OTA. 25 grams of finely powdered chocolate samples was extracted in $200 \mathrm{~mL}$ of $2 \% \mathrm{NaHCO}_{3}$ solution. The mixture was homogenized for $20 \mathrm{~min}$ using Ultra-Turrax Homogenizer (Polytron, Switzerland). Homogenized solutions were filtered through Whatman Number 2 filter paper and Whatman 934-A $\mathrm{H}$ glass microfiber filters. The chocolate sample filtrate $(9 \mathrm{~mL})$ was mixed with phosphate buffer saline $(30 \mathrm{~mL})$ and applied to an Ochratest WB immunoaffinity column (Vicam, USA) at a flow rate of $1 \mathrm{~mL} / \mathrm{min}$. The column was washed with distilled water and OTA eluted with acetic acid and methanol (98:2 v/v, $2 \mathrm{~mL})$ into the amber vials. The eluted substance was evaporated to dryness at $40^{\circ} \mathrm{C}$ under a stream of $\mathrm{N}_{2}$, and the dry residue was redissolved in mobile phase.

HPLC Parameter. An Agilent 1100 series HPLC system (Agilent Technologies, USA) was used with a fluorescence detection set at $333 \mathrm{~nm}$ excitation and $477 \mathrm{~nm}$ emission for 
TABLE 1: Recoveries of mycotoxins from spiked chocolates.

\begin{tabular}{|c|c|c|c|c|c|c|c|c|c|c|}
\hline \multirow{2}{*}{$\begin{array}{l}\text { Spike } \\
\text { level } \\
(\mu \mathrm{g} / \mathrm{kg})\end{array}$} & \multicolumn{2}{|c|}{ Aflatoxin $B_{1}$} & \multicolumn{2}{|c|}{ Aflatoxin $B_{2}$} & \multicolumn{2}{|c|}{ Aflatoxin $\mathrm{G}_{1}$} & \multicolumn{2}{|c|}{ Aflatoxin $\mathrm{G}_{2}$} & \multicolumn{2}{|c|}{ Ochratoxin A } \\
\hline & $\begin{array}{c}\text { Mean } \\
\text { recovery } \\
(\%)\end{array}$ & RSD (\%) & $\begin{array}{c}\text { Mean } \\
\text { recovery } \\
(\%)\end{array}$ & RSD (\%) & $\begin{array}{c}\text { Mean } \\
\text { recovery } \\
(\%)\end{array}$ & RSD (\%) & $\begin{array}{c}\text { Mean } \\
\text { recovery } \\
(\%)\end{array}$ & RSD (\%) & $\begin{array}{c}\text { Mean } \\
\text { recovery } \\
(\%)\end{array}$ & $\operatorname{RSD}(\%)$ \\
\hline 2 & 91.5 & 4.34 & 84.7 & 3.25 & 77.8 & 4.65 & 79.8 & 2.82 & 92.8 & 1.65 \\
\hline 4 & 55.6 & 2.72 & 60.9 & 5.12 & 58.6 & 1.40 & 59.2 & 2.54 & 63.7 & 3.48 \\
\hline 6 & 88.9 & 1.70 & 70.5 & 2.02 & 91.9 & 1.17 & 92.9 & 1.83 & 91.9 & 2.16 \\
\hline
\end{tabular}

ochratoxin A. A reverse phase Agilent Technologies C18 $(4.6 \times 250 \mathrm{~mm}, 5.0 \mu \mathrm{m})$ column was employed. The mobile phase used for OTA analysis was water:acetonitrile: acetic acid $(50 \mathrm{~mL}: 50 \mathrm{~mL}: 01 \mathrm{~mL})$. The flow rate was $1 \mathrm{~mL} / \mathrm{min}$ and column temperature was $40^{\circ} \mathrm{C}$. OTA standard was used for construction of a five-point calibration curve of peak areas versus concentration $(\mu \mathrm{g} / \mathrm{L})$. The injection volume was $20 \mu \mathrm{L}$ for both standard solution and sample extracts.

2.6. Statistical Analysis. All the measurements of the branded and local samples of chocolates were repeated three times and the data was statistically analyzed by using the software IBM SPSS Statistics, version 20. Regression analyses were applied to find out the coefficient of determination $\left(R^{2}\right)$. The calibration curves used for quantification were calculated by least-squares method. Samples with a concentration of total aflatoxins higher that limit of detection were considered positives, while the samples with concentrations lower than limit of detection were considered negative.

\section{Results and Discussion}

Chocolates are the most consumed sustenance in the world owing to their specific flavor and exceptional health benefits, but mycotoxin contamination results in prompt deterioration in their quality. During this research, a total 200 samples of chocolates were analyzed to evaluate the contamination level of total aflatoxins and ochratoxin A by HPLC. The mean recovery $\%$ and RSD values at different spike levels are calculated and summarized in Table 1.

The studied compounds were recognized by using retention time that matches against those of the calibration standards while the quantification was achieved by means of peak area that match the standards. The HPLC chromatograms of AFs and OTA standards were displayed in Figures 1 and 2.

3.1. Mycotoxin Contents of Branded Chocolates. Occurrence of total aflatoxins and OTA was noticed in almost all the examined branded chocolate samples. The quantitative analysis of mycotoxin (aflatoxins and OTA) in chocolates showed that, in the branded samples, dark chocolates contained the highest concentration of aflatoxin $(2.27 \mu \mathrm{g} / \mathrm{kg})$ followed by milk and bitter chocolates $(1.31 \mu \mathrm{g} / \mathrm{kg}$ and $0.97 \mu \mathrm{g} / \mathrm{kg}$, resp.), while white chocolates showed $0.15 \mu \mathrm{g} / \mathrm{kg}$ of total aflatoxins which is the lowest concentration detected. The maximum level of OTA was observed in white chocolates $(2.06 \mu \mathrm{g} / \mathrm{kg})$ and $0.90 \mu \mathrm{g} / \mathrm{kg}$ of OTA was detected in the sample of dark

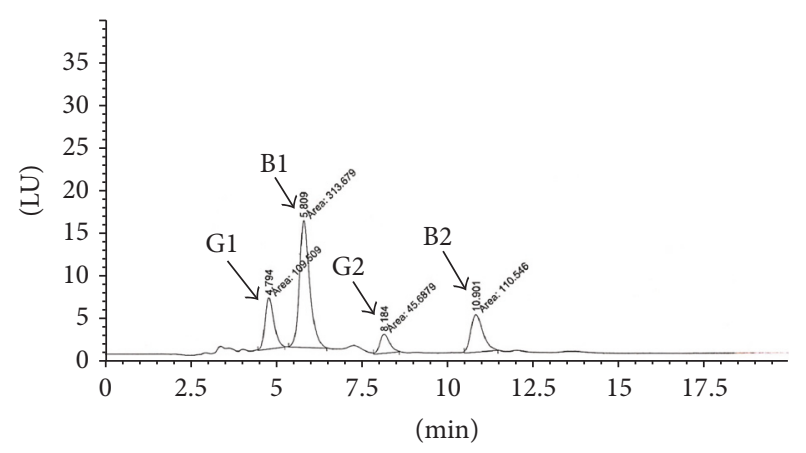

FIGURE 1: HPLC chromatogram of aflatoxin Standards.

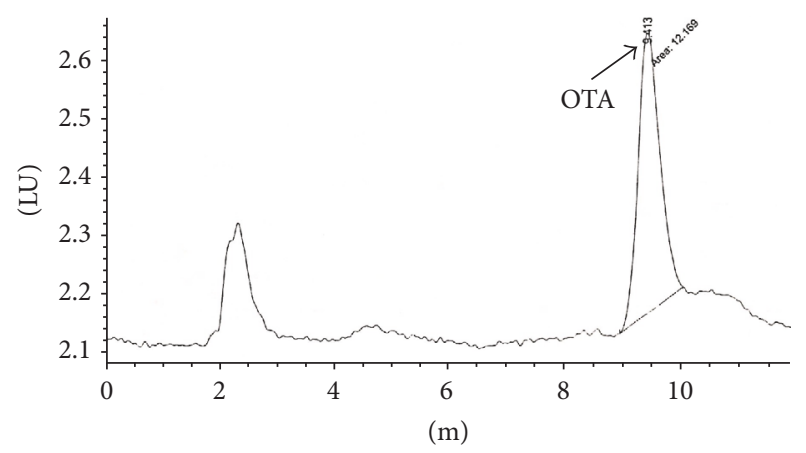

FIGURE 2: HPLC chromatogram of OTA standard.

chocolate which was the lowest concentration in all the examined branded chocolates. Illustrative chromatogram of branded samples is displayed in Figure 3. The concentration of total aflatoxins and ochratoxin A of branded and local chocolates is listed in Tables 2 and 3.

3.2. Mycotoxin Contents of Local Chocolates. HPLC chromatogram of local sample is presented in Figure 4. In the local samples of chocolates, the highest concentration of total aflatoxins was detected in the samples of white chocolates $(3.35 \mu \mathrm{g} / \mathrm{kg})$ though the samples of dark chocolate exhibited the lowest concentration of $2.55 \mu \mathrm{g} / \mathrm{kg}$ of total aflatoxins. The samples of dark chocolate displayed the maximum level of OTA, that is, $3.48 \mu \mathrm{g} / \mathrm{kg}$, whereas $1.28 \mu \mathrm{g} / \mathrm{kg}$ of OTA was detected in the samples of bitter chocolates which is labelled to be the lowest concentration in all the examined chocolates and its chromatogram is displayed in Figure 5. 


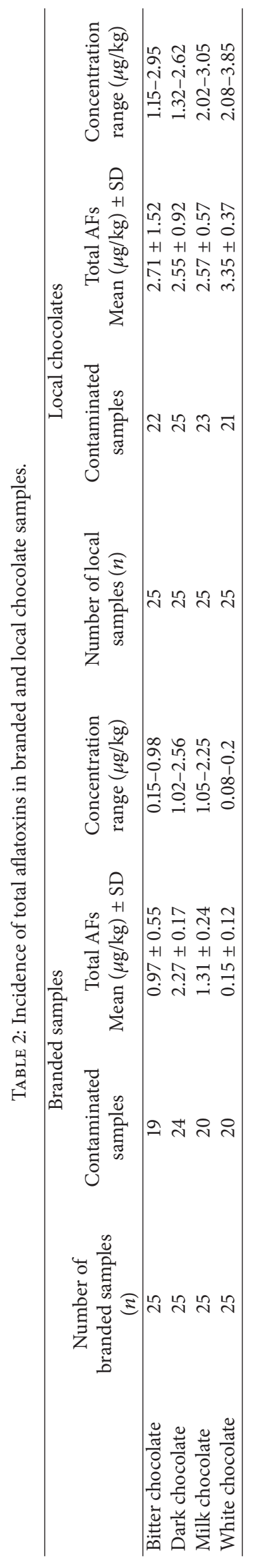




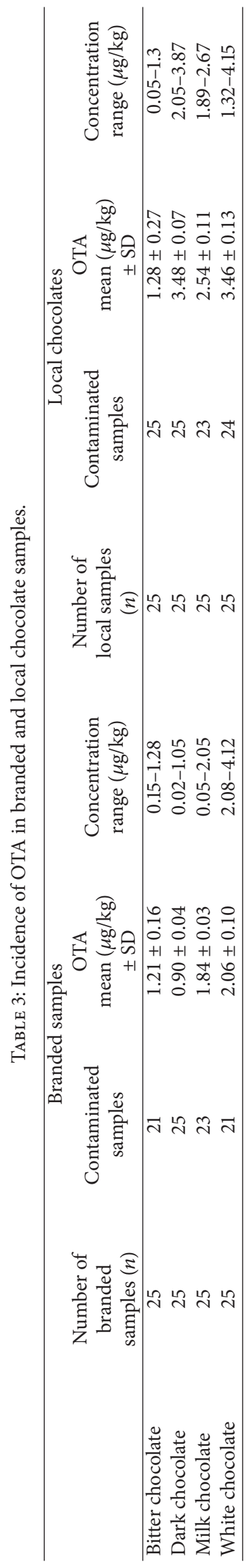




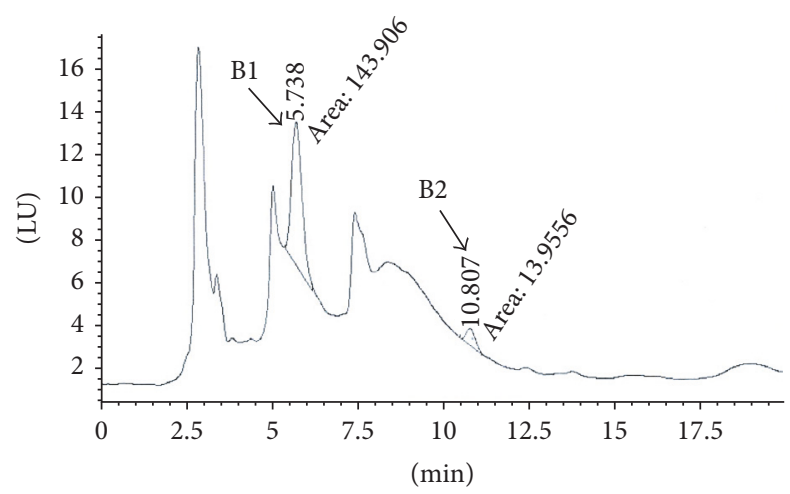

FIGURE 3: HPLC chromatogram of branded chocolate sample.

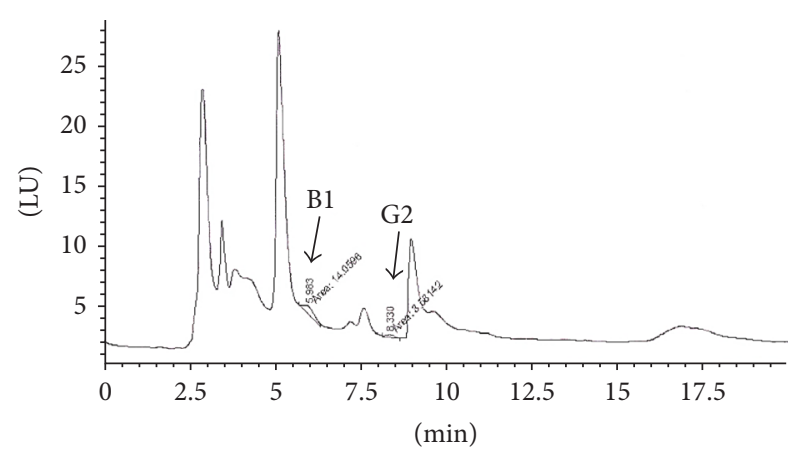

FIGURE 4: HPLC chromatogram of local chocolate sample.

A comparison between local and branded samples of chocolates disclosed that the local samples contained total aflatoxins and OTA in greater concentration as compared to the branded samples and is displayed in Figures 6 and 7.

The incidence of ochratoxin $\mathrm{A}$ and aflatoxins in the chocolate has been reported in the last era throughout the world and is an attention-seeking topic of concern for researchers. The cooccurrence of aflatoxins and ochratoxin A in the chocolate samples was reported in studies carried out in Brazil. The authors observed aflatoxins in $80 \%$ of the examined samples. A strong relationship was observed between the occurrence of ochratoxigenic fungi and the ochratoxin A content in the chocolate samples $[3,13,23]$. One hundred and seventy-nine, out of the 300 samples analyzed, were positive for ochratoxin A contamination, representing $60 \%$ of the purchased products marketed in Italy [2]. Eighty-five samples of cocoa products used in Canada were analyzed for ochratoxin A and aflatoxins by HPLC. All the examined samples displayed positive result for ochratoxin A and aflatoxin contamination [19].

The results of current research clearly exhibited that the level of total aflatoxins and ochratoxin A contamination in chocolates is quite high in Pakistan and comparable with the literature reported [3]. Many factors will determine the incidence of the mycotoxins in a chocolate sample. The presence of mycotoxins producing fungi during the handling of cocoa at producing farms was described in literature [24].

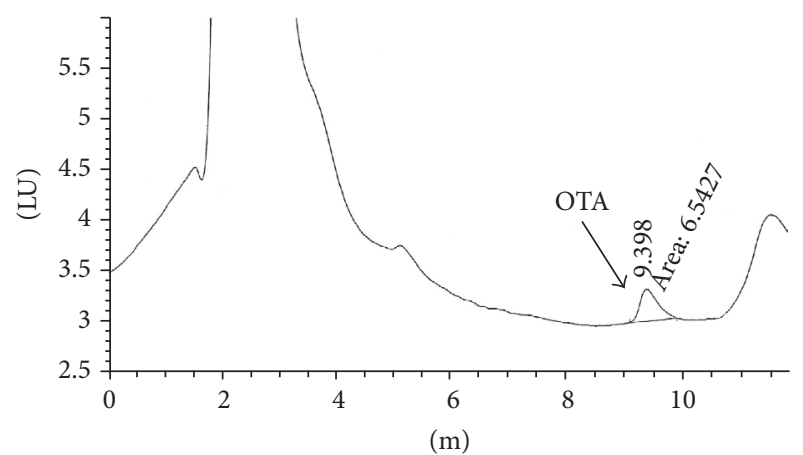

FIgURE 5: HPLC chromatogram of chocolate sample.

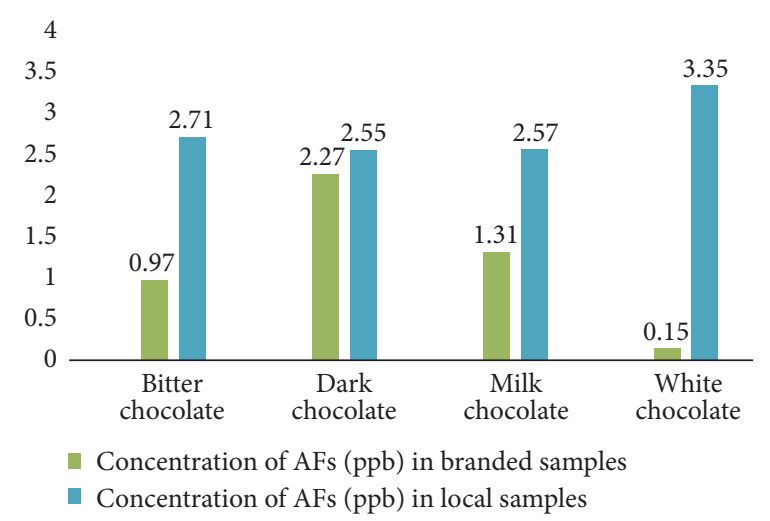

Figure 6: Concentration of total AFs in branded and local samples of chocolates.

The sun-drying stage is a basic stride for mycotoxin generations in cocoa, since during drying, besides the presence conceivably toxigenic species, there is still enough water to support contagious development and mycotoxin production $[3,5]$. Pakistan has hot and damp kind of environment; the probabilities of the incidence of critical mycotoxins are more probable in the food.

The high level of mycotoxin contamination in chocolate is a serious health hazard and the influenced authorities should consider this issue of contamination urgently. For consumer safety, necessary measures must be reinforced in all processing phases to take out the level of mold defilement. Moreover, maximum limits of mycotoxins for all food products should be specifically established in the country. Publications are accessible with the mycotoxins contamination of chocolates in different realms [23] but not a single one from Pakistan.

The additional researches must be required in order to collect enough records on the existence of mycotoxins and with the purpose of reducing the amount of these in different chocolate bars that are the most consumed in the community.

\section{Conclusion}

The present study provides the first description of the mycotoxin contamination in chocolates from Pakistan. Taking all the information into consideration, it is concluded that the defilement of chocolates with mycotoxins is quite high 


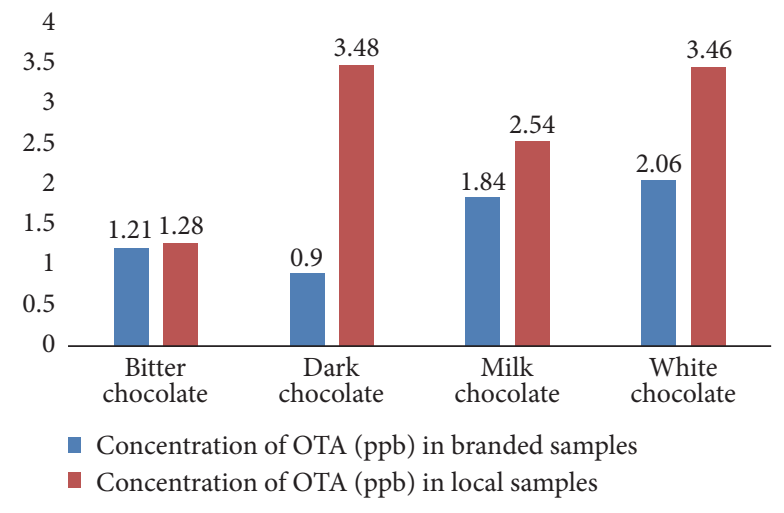

FIGURE 7: Concentration of OTA in branded and local samples of chocolates.

in local samples in contrast with branded chocolates. So it is necessary to create awareness among people about the contamination caused by mycotoxins. To guarantee the safety of consumers, the concerned administrative authorities are recommended to check this adverse issue of food contamination and quality control method of food ought to be practiced.

\section{Conflicts of Interest}

The authors declare that there are no conflicts of interest regarding the publication of this paper. It is confirmed that Department of Toxicology, Quality Operations Laboratory, University of Veterinary and Animal Sciences, did not provide any funding and did not lead to any conflicts of interest regarding the publication of this manuscript. There are no any other possible conflicts of interest in the manuscript.

\section{Acknowledgments}

The authors acknowledge the Department of Toxicology, Quality Operations Laboratory, University of Veterinary and Animal Sciences, for providing Laboratory facilities for the analysis of mycotoxins.

\section{References}

[1] J. S. Bonvehí, "Occurrence of ochratoxin A in cocoa products and chocolate," Journal of Agricultural and Food Chemistry, vol. 52, no. 20, pp. 6347-6352, 2004.

[2] C. Brera, F. Debegnach, B. De Santis et al., "Ochratoxin A in cocoa and chocolate products from the Italian market: occurrence and exposure assessment," Food Control, vol. 22, no. 10, pp. 1663-1667, 2011.

[3] M. V. Copetti, B. T. Iamanaka, J. L. Pereira, M. H. Fungaro, and M. H. Taniwaki, "Aflatoxigenic fungi and aflatoxin in cocoa," International Journal of Food Microbiology, vol. 148, no. 2, pp. 141-144, 2011.

[4] P. Manda, D. S. Dano, J. H. Kouadio et al., "Impact of industrial treatments on ochratoxin A content in artificially contaminated cocoa beans," Food Additives and Contaminants. Part A Chemistry, Analysis, Control, Exposure and Risk Assessment, vol. 26, no. 7, pp. 1081-1088, 2009.
[5] B. Kabak and A. D. W. Dobson, "Biological strategies to counteract the effects of mycotoxins," Journal of Food Protection, vol. 72, no. 9, pp. 2006-2016, 2009.

[6] O. Kawamura and A. Hamada, Determination of aflatoxins in cacao products by immunoaffinity column-HPLC methods. Kagawa Daigaku Nogakubu Gakujutsu Hokoku.114:8588, Determination of aflatoxins in cacao products by immunoaffinity column-HPLC methods. Kagawa Daigaku Nogakubu Gakujutsu Hokoku.114, 85-88, 2009.

[7] N. A. Al-Hazmi, "Determination of Patulin and Ochratoxin A using HPLC in apple juice samples in Saudi Arabia," Saudi Journal of Biological Sciences, vol. 17, no. 4, pp. 353-359, 2010.

[8] M. A. Egbuta, C. A. Chilaka, J. Z. Phoku, M. Mwanza, and M. F. Dutton, "Co-contamination of Nigerian cocoa and cocoabased powder beverages destined for human consumption by mycotoxins," Studies on Ethno-Medicine, vol. 7, no. 3, pp. 187194, 2013.

[9] M. S. Rathore and N. Shekhawat, "Incredible Spices of India from Traditions to Cuisine," American Journal of Botany, pp. 8589, 2008.

[10] S. Fujii, R. M. R. Ribeiro, M. B. D. S. Scholz et al., "Reliable indirect competitive ELISA used for a survey of ochratoxin A in green coffee from the North of Paraná State, Brazil," Food Additives and Contaminants, vol. 23, no. 9, pp. 902-909, 2006.

[11] H. M. L. J. Joosten, J. Goetz, A. Pittet, M. Schellenberg, and P. Bucheli, "Production of ochratoxin A by Aspergillus carbonarius on coffee cherries," International Journal of Food Microbiology, vol. 65, no. 1-2, pp. 39-44, 2001.

[12] K. Jørgensen, "Occurrence of ochratoxin A in commodities and processed food-a review of EU occurrence data," Food Additives and Contaminants, vol. 22, no. 1, pp. 26-30, 2005.

[13] M. V. Copetti, J. L. Pereira, B. T. Iamanaka, J. I. Pitt, and M. H. Taniwaki, "Ochratoxigenic fungi and ochratoxin A in cocoa during farm processing," International Journal of Food Microbiology, vol. 143, no. 1-2, pp. 67-70, 2010.

[14] M. B. M. Ferraz, A. Farah, B. T. Iamanaka et al., "Kinetics of ochratoxin A destruction during coffee roasting," Food Control, vol. 21, no. 6, pp. 872-877, 2010.

[15] S. Kumagai, M. Nakajima, S. Tabata et al., "Aflatoxin and ochratoxin A contamination of retail foods and intake of these mycotoxins in Japan," Food Additives and Contaminants. Part A Chemistry, Analysis, Control, Exposure and Risk Assessment, vol. 25, no. 9, pp. 1101-1106, 2008.

[16] S. Romani, G. G. Pinnavaia, and M. Dalla Rosa, "Influence of roasting levels on ochratoxin A content in coffee," Journal of Agricultural and Food Chemistry, vol. 51, no. 17, pp. 5168-5171, 2003.

[17] A. El Khoury and A. Atoui, "Ochratoxin A: general overview and actual molecular status," Toxins, vol. 2, no. 4, pp. 461-493, 2010.

[18] A. Napolitano, V. Fogliano, A. Tafuri, and A. Ritieni, "Natural occurrence of ochratoxin A and antioxidant activities of green and roasted coffees and corresponding byproducts," Journal of Agricultural and Food Chemistry, vol. 55, no. 25, pp. 1049910504, 2007.

[19] A.-M. Turcotte, P. M. Scott, and B. Tague, "Analysis of cocoa products for ochratoxin A and aflatoxins," Mycotoxin Research, vol. 29, no. 3, pp. 193-201, 2013.

[20] Z. Zheng, J. Hanneken, D. Houchins, R. S. King, P. Lee, and J. L. Richard, "Validation of an ELISA test kit for the detection of ochratoxin A in several food commodities by comparison with HPLC," Mycopathologia, vol. 159, no. 2, pp. 265-272, 2005. 
[21] M. V. Copetti, B. T. Iamanaka, J. L. Pereira, D. P. Lemes, F. Nakano, and M. H. Taniwaki, "Determination of aflatoxins in by-products of industrial processing of cocoa beans," Food Additives and Contaminants. Part A Chemistry, Analysis, Control, Exposure and Risk Assessment, vol. 29, no. 6, pp. 972-978, 2012.

[22] M. Thompson, S. L. R. Ellison, and R. Wood, "Harmonized guidelines for single-laboratory validation of methods of analysis (IUPAC Technical Report)," Pure and Applied Chemistry, vol. 74, no. 5, pp. 835-855, 2002.

[23] M. V. Copetti, B. T. Iamanaka, J. L. Pereira, D. P. Lemes, F. Nakano, and M. H. Taniwaki, "Co-occurrence of ochratoxin A and aflatoxins in chocolate marketed in Brazil," Food Control, vol. 26, no. 1, pp. 36-41, 2012.

[24] M. V. Copetti, B. T. Iamanaka, J. I. Pitt, and M. H. Taniwaki, "Fungi and mycotoxins in cocoa: from farm to chocolate," International Journal of Food Microbiology, vol. 178, pp. 13-20, 2014. 

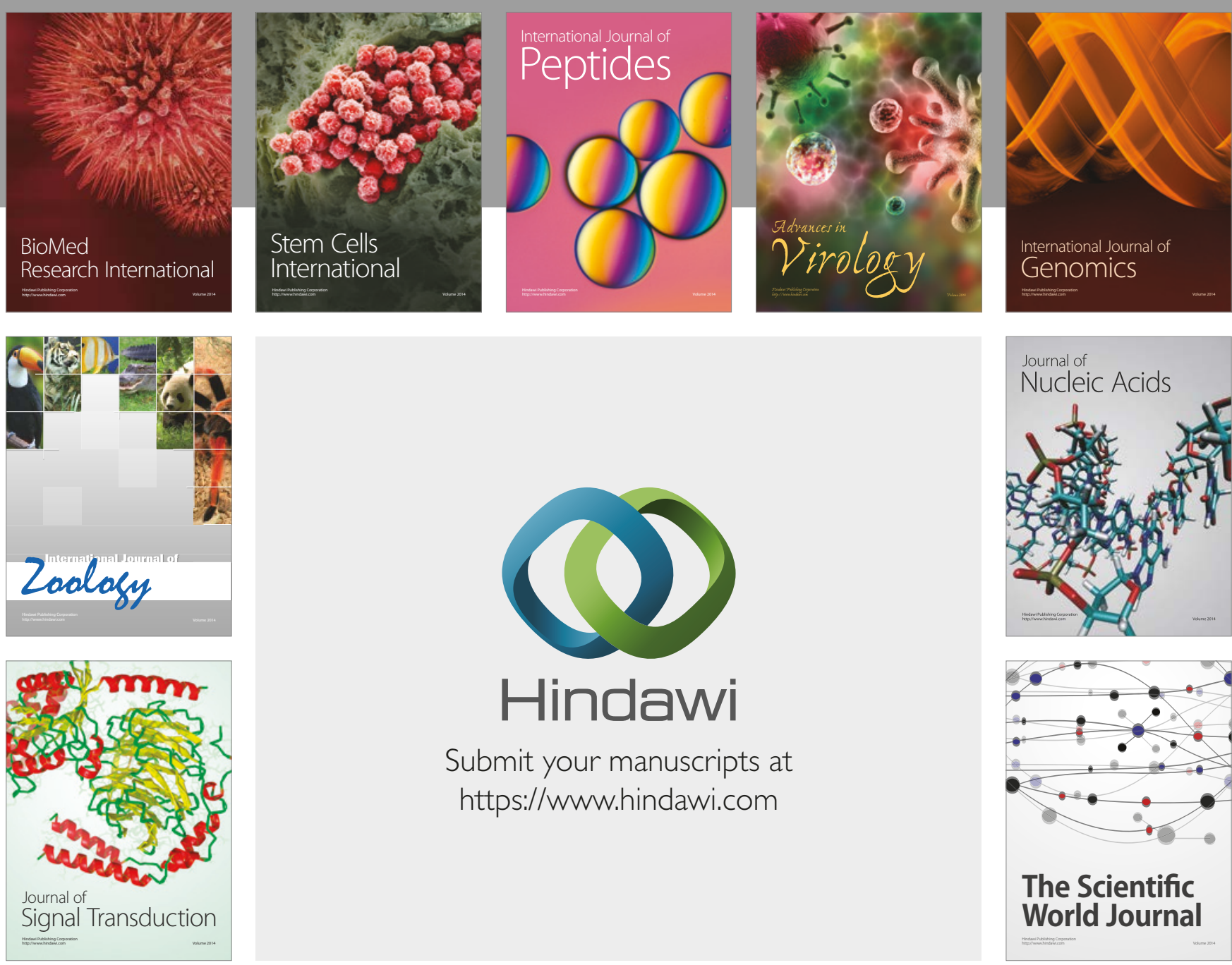

Submit your manuscripts at

https://www.hindawi.com
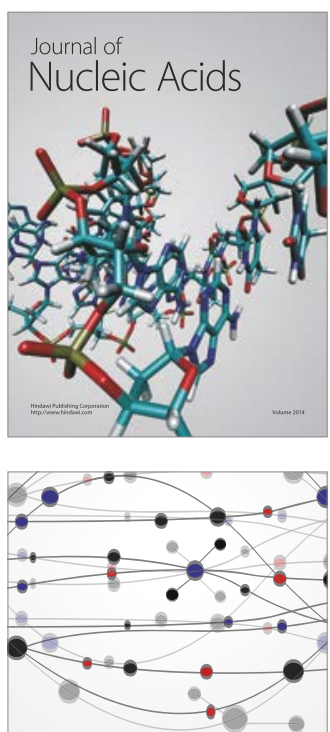

The Scientific World Journal

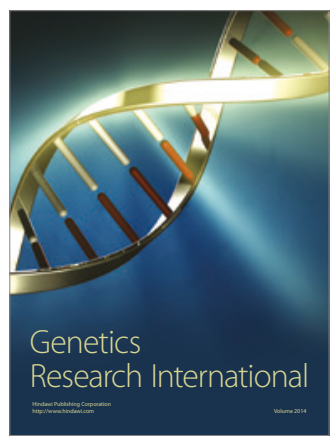

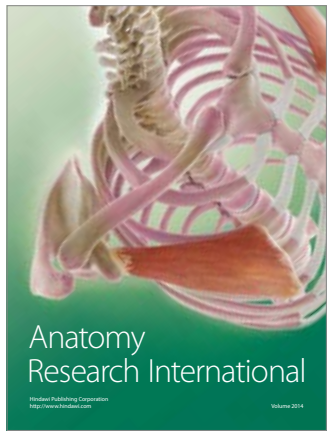

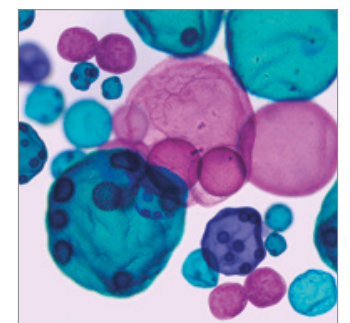

International Journal of Microbiology
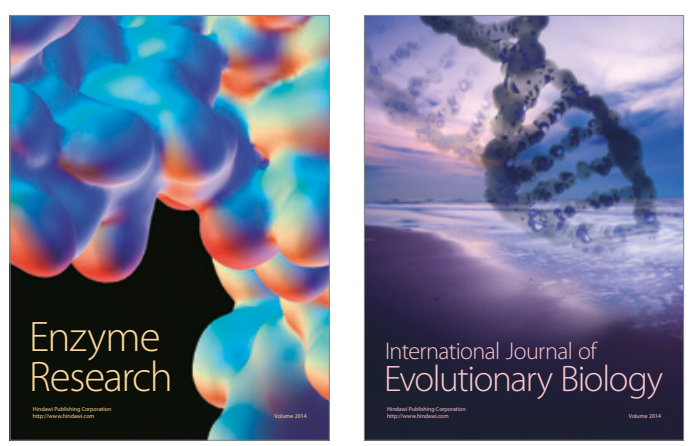
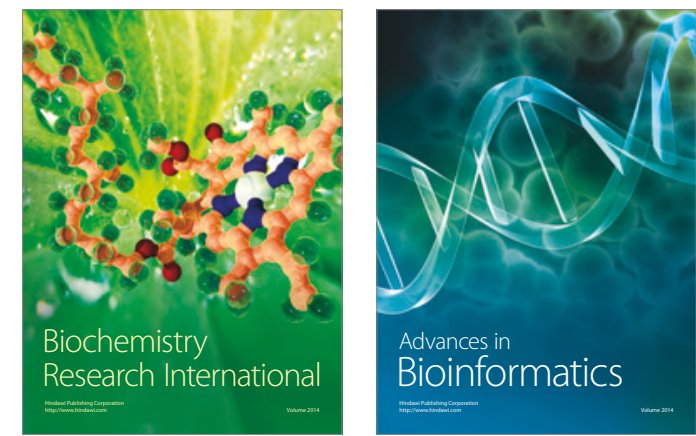

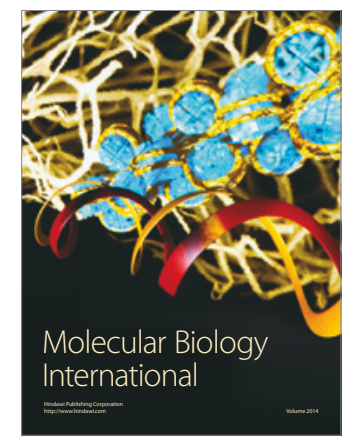

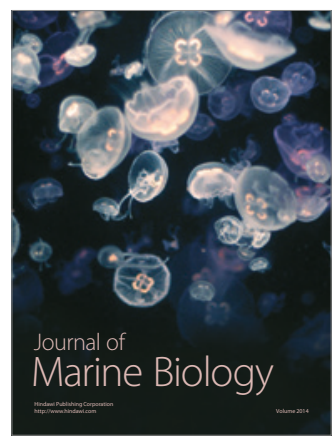

